\title{
Primary Investigation on the Reform of the Laboratory Management Mode in Higher Vocational Education Colleges
}

\author{
Chang Ming \\ Department of Electronic Engineering \\ Changchun Institute of Engineering Technology \\ Changchun, 130117, China \\ wyywyqn@163.com \\ Jin Dingyun \\ Department of Electronic Engineering \\ Changchun Institute of Engineering Technology \\ Changchun, 130117, China
}

\author{
Zhou Xun \\ Department of Electronic Engineering \\ Changchun Institute of Engineering Technology \\ Changchun, 130117, China \\ Tu Chao \\ Department of Electronic Engineering \\ Changchun Institute of Engineering Technology \\ Changchun, 130117, Chin
}

\author{
Gao Fei \\ Department of Electronic Engineering \\ Changchun Institute of Engineering Technology \\ Changchun, 130117, China
}

\begin{abstract}
The main target of talent training in Higher Vocational Education Colleges is to train students' posts competencies. Compared with colleges with academic credentials education, they pay more attention to the practical ability of students. Therefore, the function of the laboratory which can train the creative spirit and innovative ability, and the experimental facilities should be put into full play. The rate of equipment utilization should be increased. Now the management mode of laboratory is still "closed". Students could only use labs within the class hours. Except these hours, the labs are always closed. Therefore, the reform of laboratory management mode in our college will be the key problem which needs solving right now. The report mainly researches the necessity of the laboratory opening and the function, operating management system and responsible mechanism of open laboratory. How to train the innovative ability of students is also analyzed.
\end{abstract}

Keywords—Laboratory; Open; InnovativeAbility; Management mode

\section{INTRODUCTION}

The main target of talent training in Higher Vocational Education Colleges is to train students' posts competencies. Compared with colleges with academic credentials education, they pay more attention to the practical ability of students. Therefore, the function of the laboratory which can train the creative spirit and innovative ability, and the experimental facilities should be put into full play. The rate of equipment utilization should be increased. Now the management mode of laboratory is still "closed". Students could only use labs within the class hours. Except these hours, the labs are always closed. Therefore, the reform of laboratory management mode in our college will be the key problem which needs solving right now.

The author believes that to play the educational function of laboratory, an open mode of management should be developed. To make great efforts in laboratory opening, not only should the necessity and basic function of laboratory opening be explicit, but the management work of laboratory opening should be emphasized, so as to improve the effect of laboratory opening and the quality of experimental teaching. The report is planned to discuss the views on the construction and management of open laboratory based on the experience of practical work[1]. 


\section{THE NECESSITY OF LABORATORY OPENING}

Traditional laboratory teaching attaches to the theory teaching in classroom. The periods and contents with the single level of experiment are closed and limited. Replication experiment is the main content. However, the replication experiment, which is single in content, fixed in experimental procedures, just plays instructional role in knowing the preliminary content of experiment for students. Students can go to the laboratories within the stipulated time and conduct an experiment according to the teaching program. When finishing the experiment, the labs are closed so that students have few opportunities to enter into the labs. There are a lot of shortcomings. First, the resources in the labs couldn't be used entirely, such as the low utilization rate of instrument and equipment, the waste of houses and resources. Second, the times for students to enter into the labs are limited. When mistakes appeared, it's difficult for them to redo it. Third, it isn't suitable for the flexible requirement of experimental lessons. Forth, the number of experiments is limited. There are only compulsory experiments but no optional experiments. During the whole process, students have few opportunities to do the experiments independently, let alone the experiments out of the teaching program and other innovative programs. Based on the shortcomings above, closed-off management of laboratory, the mode of replication experiment and the few opportunities for students to practice go against the students training of practical ability and innovation consciousness.

Therefore, we need to reform the existing closed-off management mode of laboratory, widen the laboratory opening and develop optional experiment programs, strengthen the practice and train the innovative spirits and creative thoughts of students, improve the quality of teachers, which are good for putting the function of laboratory into full play[2].

\section{THE FUNCTION OF OPEN LABORATORY}

The main content of the open laboratory reform are determined by the specific circumstance of the colleges and the targets that need open. We concluded the following functions that the open laboratory should have after our research and investment for a period.

\section{A To Promote the Training of Experiment Skills}

Different experiments should be chosen to conduct by students according to the characters of different majors and levels at first. The labs should be provided with corresponding equipment, facilities and instructions. Students could conduct experiments in the labs according to the schedule published by the labs. During the open hours, teachers could also instruct and test students, so that they can finish their work of skills testing and grades enrollment, which can provide a forceful and reliable evidence for the comprehensive quality assessment of students.

\section{$B$ To Provide a Platform for the Comprehensive and}

Contrivable Experiments Which Couldn't be Finished in

Class

Our college has paid more and more attention to the posts training. To have strong posts competencies, the comprehensive qualities of students must be improved. Thus we should develop some comprehensive and contrivable experiments in a good time moderately. Limited by class hours, many experiments couldn't be finished during the stipulated hours generally. Students now could take advantage of the open hours, and finish these experiments. It's good for improving the quality of comprehensive and contrivable experiments.

\section{To Promote a Platform for Students to Do Innovative}

\section{Experiments}

The colleges should encourage students to have innovative activities in labs. Students' interests toward study can be seen from their participation. It can also prove their learning ability and level. Meanwhile, we can issue the open research topic of teachers' scientific research project and invite excellent students to participate in the project in labs in the early stage, which can both train the innovative ability of students and expand the forces of science and research in every college.

D The establishment of digital learning environment by the open laboratory platform

The traditional teaching method of "blackboard and chalk" must not be adapted to the information age, but the CAI courseware of the early multimedia combination, although to some extent, improved the teaching environment, but because of the different media, there is no qualitative change in the teaching relationship. In the digital learning environment, the learning resources are rich, which can be easily adapted to the needs of different levels of students, teaching mode and students' learning strategies, the whole learning process to students as the center, to meet the students' personal learning interest; Because of the characteristics of digital learning environment, it is easy to organize the teaching content in the form of modular, and it can be used to make the teaching content according to the practical problems. It can be used to probe into the basic knowledge, skills, and solve the problem。 Through the task driving mode, knowledge learning and the actual situation of the contact more clearly, the same learning materials can be used in different ways, to exercise the students' ability to solve problems, to consolidate the knowledge learned。

\section{THE RESEARCH ON THE OPERATING MECHANISM OF OPEN}

\section{LABORATORY}

How does open laboratory open authentically? The author believes that there are three factors, that is, the overall opening in time, contents and subjects of experiment. However, how to maximize the function of open laboratory? How to put the students training of practical and innovative abilities into practice? Combined with the reality of our work and imitate the successful experience of similar colleges, the author made a preliminary research on the operating mechanism of open laboratory[3].

The research on the operating system of open laboratory. To guarantee the normal working of open laboratory, the rules and regulations of administration and system of post 
responsibility must be built, which include the administrative system of security and apparatus, responsibilities of technicians, experimental regulations, funding system and assessment system, etc. Laboratory management and maintenance of the effect of how to directly affect the degree of laboratory opening, The biggest difference between open laboratory and conventional teaching experiment is: At the same time to enter the laboratory level of the students, the difference between the experimental activities, the opening time of the laboratory, the high rate of the instrument and equipment, which need to be equipped with a teacher, responsible for the supervision and management of the laboratory order; Secondly, to develop a series of management measures, such as the students to do the experiment to implement an appointment and registration system, to enter the laboratory after the completion of the record sheet, after the experiment, the experiment report[4].

The research on the management team of open laboratory. After opening entirely towards students, the volume of work would be largely increased. Laboratory management and maintenance of the effect of how to directly affect the degree of laboratory opening The biggest difference between open laboratory and conventional teaching experiment is: At the same time to enter the laboratory level of the students, the difference between the experimental activities, the opening time of the laboratory, the high rate of the instrument and equipment, which need to be equipped with a teacher, responsible for the supervision and management of the laboratory order. Secondly, to develop a series of management measures, such as the students to do the experiment to implement an appointment and registration system, to enter the laboratory after the completion of the record sheet, after the experiment, the experiment report. Therefore, we should select excellent students as administrator assistants. They will be combined with full-time experimental teachers whose management plays the main role. Administrator assistants' job is to assist teachers. They mainly maintain the equipment, facilities and network in the labs, enroll the experimental grades of students, so that their senses of ownership and comprehensive ability would be improved.

The research on the students' management system of open laboratory. Students who enter into the open laboratory and conduct the experiment must obey the following regulations: (1) Before entering into the labs, everyone should review the experiment and keep the announcements of facilities in mind. The habits of standard operation should be formed at the beginning. (2)After entering into the labs, students should inspect the equipment at first. When meeting difficulties, students should ask help from administrative staffs.(3)During the experiment, students should obey the management and instructions of administrative staffs. Those who break the rules and are unadvisable would lose the rights to do experiments. (4) Those who break the rules and then cause a loss will be penalized and pay a fortune according to the relevant regulations. Students should be administrated strictly. Meanwhile, the correspondent incentive system should be built up to arouse the enthusiasm and initiative of students when entering into the labs[5].

The research on the assessment system of open laboratory. When the labs open, an effective assessment system must be built so as to play an incentive and guiding role. It plays a guiding role for administrative staffs and students in the labs. The system guarantees the authenticity but not the formal open so that the open laboratory could work normally.

\section{THE RESEARCH ON RESPONSIBILITIES MECHANISM OF}

\section{OPEN LABORATORY}

The open laboratory should be applied and drawn up a specific plan according to the overall plan of lab construction and the self-condition of the specific labs in each unit by corresponding departments. After the discussion of corresponding departments, it could be put into practice when the competence department of colleges finishes examining and approving.

The open laboratory should arrange the teaching contents, develop the experimental program, and commit the teaching tasks and the management of opening. The college should provide the funds for the normal operation, maintenance, and renovation in advance, and inspect and assess this equipment regularly. The staffs in the open laboratory should make preparations for apparatus, lab materials and experimental environment based on the open plan. When the lab is opened, the experimental instructors and technicians should maintain the teaching order, notice the experimental security and record the details of opening. Students need to be ready for the experiment before entering. And they should read relevant references and materials under teachers' instruction, and design the experimental program and get acquainted with the design performance. When being allowed by instructors, students can do the experimental research in the labs. During the experiment, students should obey all the regulations in the labs. When finishing the experiment, students should submit their experimental results to their instructors, who will correct their reports and give their correspondent scores[6].

\section{CONCLUSION}

The open mode of experimental teaching breaks the concentrated mode of experimental teaching centered on instructors, which must bring a series of new problems for the teaching management in colleges. These colleges need to explore and research constantly. In brief, the fundamental foothold of laboratory opening is to consolidate the basic theory, train the abilities of analyzing and solving problems, enhance the innovative abilities of students. Through the open laboratory, students could have more time and chances to enter into the labs. They can use what they have learned to conduct the experiments independently with their minds and hands.

\section{REFERENCES}

[1] M G Abou-Ali,M Khamis TIREDDX:an Intergrated Intelligent Defects Diagnostic System for Tire Production and Service.Expert Systems with Applications[J].2003,24(3):247-259

[2] M E Yahia, R Mahmod,N Sulaiman,et al.Rough Neural Expert System[J].Exprt Systems with Applications,2000,18(2):87-99

[3] KeDong Li, Digitalization Learning (Book One), The Core of Integration about Information Technology and Digitalization[J], Audio-visual education research, 2001 (8) :46-49 (In Chinese). 
[4] Dongming Xu,Huaiqing Wang,Minhong Wang. A conceptual model of personalized virtual learning environments[J]. Expert Systems with Applications, 2005,(29):525-534.

[5] XiaoMing Li, Reflections on the Construction of Digitalization Learning Environment,Journal of changchun University of Traditional chinese Medicine,vol. 26,12,2010. (In Chinese)
[6] Silvia Schiaffino, Patricio Garcia, Analia Amandi.e Teacher:Providing personalized assistance to e-Learning students[J]. Co mputers \& Education 2008,(51):1744-1754. 